\title{
Translating Metaphorical Expressions in Political Discourse: A Comparative Conceptual Study (English - Arabic)
}

\author{
Mansour K. Thajeel Aldanani \\ Department of Physics, Faculty of Science \\ University of Sumer, \\ Alrifai City, Dhi-qar, Iraq
}

\begin{abstract}
:
This paper is to analyze the conceptual metaphors underlying the metaphorical expressions in political discourse, it explores the role of conceptual metaphors on political language and the translation strategy adopted to translate. To prove this, a cognitive approach to metaphorical expressions translation in political discourse is used. The study focuses on the analysis of the conceptual mapping of the abstract concept of politics into some other source domains. The given examples are used to argue that we use existing physical concepts to conceptualize abstract concepts for easy understanding. The results obtained reveal that the set of conceptual metaphors underlying the political expressions are almost similar in both languages in terms of the source domains used as well as their collocation patterns. The paper adds a further support to the claim that metaphors are not only a rhetorical tool used by literary men but it reflects our thinking when dealing with abstract issues in terms of concrete experience. The study has pedagogical implications for media translation students. They can compile their own glossaries using the collocation patterns relevant to each metaphorical expression.
\end{abstract}

Key Words: metaphor, cognitive concepts, collocation, political, domain, mapping

Cites as: Aldanani, M. K. T. (2018). Translating Metaphorical Expressions in Political Discourse: A Comparative Conceptual Study (English - Arabic). Arab World English Journal for Translation \& Literary Studies, 2 (4). 144-151

DOI: http://dx.doi.org/10.24093/awejtls/vol2no4.10 